\title{
Erratum to: Comparison of Visual Descriptors for 3D Reconstruction of Non-rigid Planar Surfaces
}

\author{
Michał Bednarek ${ }^{(\bowtie)}$ \\ Institute of Control and Information Engineering, \\ Poznan University of Technology, Poznań, Poland \\ michal.gr.bednarek@doctorate.put.poznan.pl
}

\section{Erratum to:}

Chapter "Comparison of Visual Descriptors for 3D

Reconstruction of Non-rigid Planar Surfaces" in:

M. Choraś and R.S. Choraś (eds.), Image Processing

and Communications Challenges 9, Advances in Intelligent

Systems and Computing 681,

https://doi.org/10.1007/978-3-319-68720-9_22

In the original version of the book, Frontmatter of Chapter 22 has been updated by including the following text in the footnote:

This work was supported by grant No. LIDER/3/0183/L-7/15/NCBR/2016 funded by The National Centre for Research and Development (Poland).

The updated online version of this chapter can be found at

https://doi.org/10.1007/978-3-319-68720-9_22 